Témoigner

Getuigen
Témoigner. Entre histoire et mémoire

Revue pluridisciplinaire de la Fondation Auschwitz

$118 \mid 2014$

Au nom des victimes. Dictature et terreur d'État en Argentine, Chili et Uruguay

\title{
Wat als de slachtoffers spoorloos zijn?
}

De zoektocht naar verdwenen gevangenen tijdens en na de dictatuur (1973-1989)

Quand la victime est introuvable. À propos des détenus-disparus au Chili et des parents qui les ont cherchés pendant et après la dictature (1973-1989)

When the victim is nowhere to be found. Chile's "disappeared" and the families that have been searching for them during and after the dictatorship (1973-1989)

\section{Antonia García Castro}

Traducteur : Antonia García Castro

\section{OpenEdition}

Journals

Édition électronique

URL : http://journals.openedition.org/temoigner/1099

DOI : 10.4000/temoigner.1099

ISSN : 2506-6390

Éditeur :

Éditions du Centre d'études et de documentation Mémoire d'Auschwitz, Éditions Kimé

Édition imprimée

Date de publication : 1 octobre 2014

Pagination : 80-87

ISBN : 978-2-84174-674-3

ISSN : 2031-4183

Référence électronique

Antonia García Castro, «Wat als de slachtoffers spoorloos zijn? », Témoigner. Entre histoire et mémoire [Online], 118 | 2014, Online op 01 octobre 2015, geraadpleegd op 23 octobre 2020. URL : http:// journals.openedition.org/temoigner/1099; DOI : https://doi.org/10.4000/temoigner.1099 


\section{CHILI}

\section{Wat als de slachtoffers spoorloos zijin?}

De zoektocht naar verdwenen gevangenen tijdens en na de dictatuur

\section{$\rightarrow$ Antonia García} Castro, Radio Universidad e Chil

(1) Vgl. Marie-Monique Robin, française, Parijs: La Découverte,

(2) Het uitgangspunt van dit
artikel is een enquête die in de jaren negentig werd gevoerd onder begeleiding van MarieClaire Lavabre (EHESS). Vgl. Antonia García Castro, La mon
lente ded disparus au Chili sous I négociation civilie-militaire (19732002), Parijs:
Larose, 2002 .
$\mathrm{R}$ 1974-1975 ontstaat de vereniging van familieleden van verdwenen (Agrupación de los familiares de detenidos desaparecidos, ( DDD) als een groep van lotgenoten: hun familieleden werden aangehouen maar nooit erkend als gevangenen door de agenten van de repressie. Wat de families toen niet beseften, is dat zij slachtoffer waren van een bijzonder ongewone misdaad Een misdaad warbij lijken verdwijnen, clandestiene operaties worden uitgevoerd en informatie wordt achtergehouden. Ben is op misdaad die bovendien niet in de Chilense wet is opgenomen. Een onzichtbare misdaad, die het makkelijk maakt voor de nilitairen om tegenstanders uit te schakelen, maa ook om grote delen van de bevolking emotioneel te gijzelen. Door het gebrek aan informatie ontstond er immers angst en verwarring.

Niet alleen in Chili, maar in heel Latijns-Amerika waren ontvoeringen een drukkingsmiddel. De staat wist via deze weg actiegroepen de mond te snoeren die de privileges van bepaalde segmenten van de samenleving aan de kaak stelden, en hun rechten gingen opeisen in de publieke ruimte. De herverdeling van de rollen was een lokale aangelegenheid en verliep in elk land op een andere manier. Toch werd er een internationale alliantie op touw gezet om dissidente stemmen te versmoren. Landen in de Zuidkerel wisse wisselden informatie uit over waarbij gedwongen verdwijning een krachtig wapen was. ${ }^{1}$ Ondanks de historische afstand kunnen dit soort praktijken in feite teruggevoerd worden tot het Nacht und Nebeldecreet, dat maarschalk Keitel tekende in 1941 en gebruikte om de tegenstanders van het regime in de bezette gebieden te onderdrukken. De nazi's deporteerden bepaalde gevangenen naar Duitsland zonder hun familie op de hoogte stellen, en hielden zo de verschrikte bevolking in hun greep.

In feite zijn er altijd twee slachtoffers bij dit soort praktijken: degene die verdwijnt, en degene die de gevolgen van de verdwijning moet dragen. Zonder zichzelf daarom volledig weo te cijferen, springen de vereniode families in Argentiniëtoch er de vorm kreeg en focust daarbij op de politieke betekenis van de misdaad, het specifieke

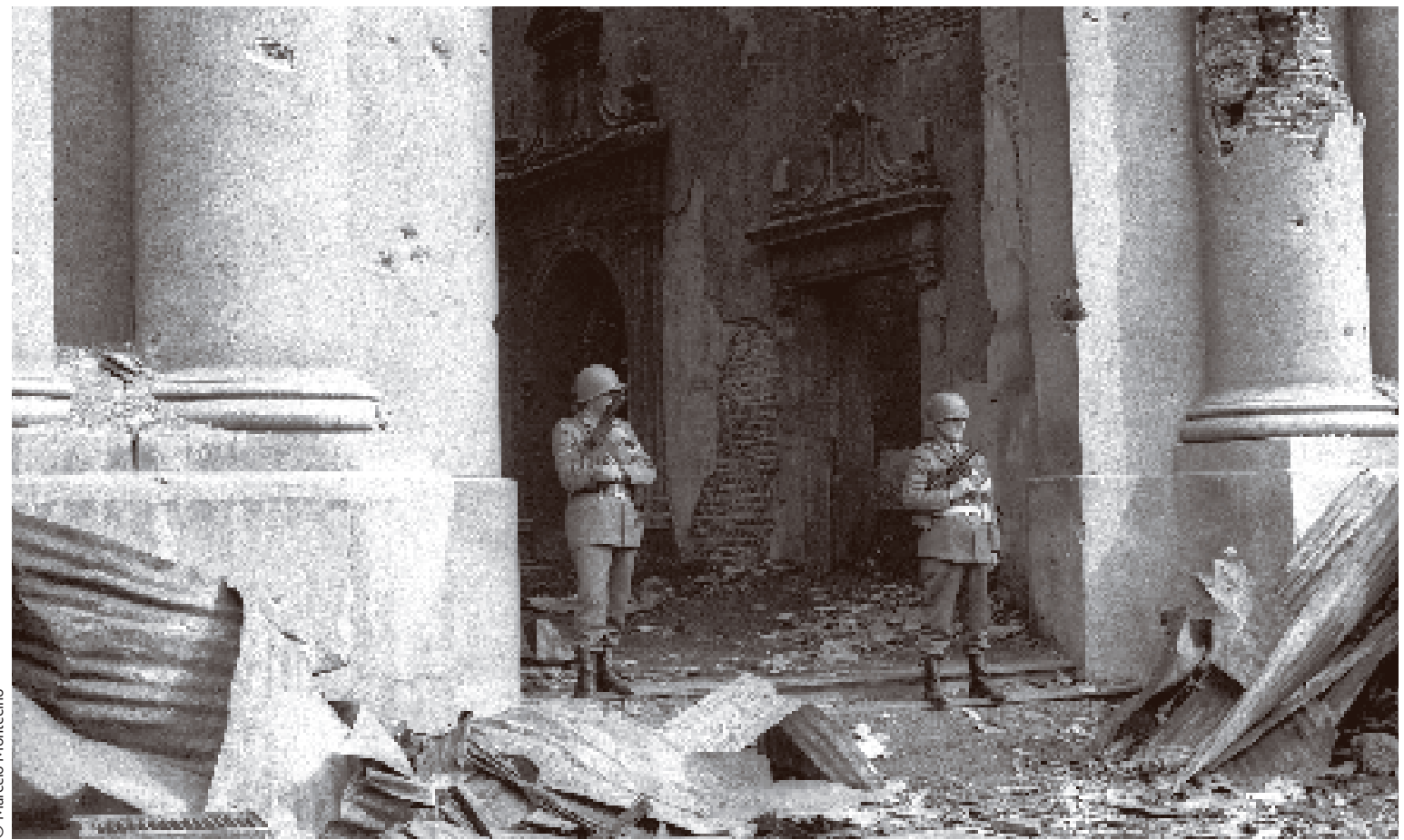

karakter van deAFDD, de moeilijkheid om de situatie onder woorden te brengen, en vervolgens de hindernissen die de familieleden recent nog moesten nemen onder het democratische bewind. Zo hopen we te begrijpen hoe de families de term 'slachtoffer' telkens hebben ingevuld - en vooral hoe ze die niet hebben ingevuld.

\section{HET POLITIEKE KARAKTER VAN DE MISDADEN}

De geschiedenis van de AFDD is een bewustwordingsproces. Tijdens de zoektocht die zij voerden in naam van hun geliefden, zijn de families steeds meer te weten gekomen over de omstandigheden van hun verdwijning. Ze hebben die inzichten op diverse manieren met de samenleving gedeeld. De dossiers die ze openden in hun juridische strijd vormen een archief van onschatbare waarde. Alles wat we vandaag weten over de 'verdwenen gevangenen'3 in Chili, hebben we in feite te danken aan de families en aan de instantie die hen altijd heeft gesteund: het Vicaría de la Solidaridad (Vicariaat van de Solidariteit) ${ }^{4}$.

Het documentatiewerk van de AFDD is relatief onbekend en staat in de schaduw van har meer'spectaculaire' acties. Door te werken op twe fronten, zijn de families van gaan besent is geen toeval dat de arrestaties plaatsvonden tijdens de staatsgreep van 1973, toen Chili na drie jaar
- Militaire staatsgreep hemberenten
(3) In Chili gebruikt men
de uitdrukking detenidos desaparecidos.

(4) In 1973 richtte de instelling op van Santiago een missie mensen te helpon die het slachtoffer waren van politieke vervolging. De Junta dwong de te heffen, en dat deed hij ook, maar een, dag later creeeerde hij meteen een nieuwe met dezelffe de dictaturu - hoewel er ook Solidariteit werd gedoogd tijdens 
socialisme weer 'terugkeerde naar de orde'. De dagen die daarop volgden kan men gerust apocalyptisch noemen: de regering werd letterlijk bestormd door de Chileense rechterzijde die hulp kreeg uit Noord-Amerika ${ }^{5}$, het presidentieel paleis werd gebombardeerd, mensen werden massaal gearresteerd, stadions werden omgevormd tot gevangenissen. Hoe grootschalig de repressie ook was, de aanhoudingen verliepen niet willekeurig. Bepaalde personen werden wel degelijk geviseerd.

Om het politieke belang van de verdwijningszaken te begrijpen, moeten we kijken naar de identiteit van de slachtoffers, en dan vooral naar hun engagement (in een naar de bepaalde partij, vakbond, vereniging), hun professionele activiteiten en de sociale groep waartoe ze behoorden. Tijdens de dictatuur ontstonden namelijk eilandjes Aan sommige wijken en families werd niet geraakt - hetzij in uitzonderlijke gevallen - omdat ze hadden meegewerkt aan de staatsgreep of ermee hadden ingestemd. Andere wijken werden net systematisch aangepakt, zoals de volkse buurten die de regering van het Volksfront (Unidad Popular, 1970-1973) steunden.

Deze elementen geven uiteraard slechts een fragmentarisch beeld van de politieke context ${ }^{6}$, maar ze staan wel centraal in het discours en de acties van de families. In hun ogen zijn de verdwenen gevangenen in de eerste plaats maatschappelijke en van een merkwaardige misdaad.

\section{ACTIEVOEREN IN NAAM VAN DE ANDER}

De Vereniging van familieleden ${ }^{7}$ van verdwenen gevangenen is volledig opgebouwd, zoals haar naam al doet vermoeden, rond een derde persoon. Ook andere verenigingen houden zich aan dit principe: geen van hen profileert zich als een vereniging van slachtoffers. ${ }^{8}$ Het slachtoffer is steeds de ander, hoezeer de familieleden zelf ook lijden onder de situatie. Centraal in hun acties en hun discours staat de persoon die zij vertegenwoordigen. In dit specifieke geval leidt dat tot een problematische situatie: hoekan men een misdaad aanklagen die mensen 'onzichtbaar' maakt?

In 1973 stuiten de families inderdaed op groot onbegip. Immers de term 'vergrenzen van die wereld bestaan er helemaal geen 'verdwenen personen'. De gevangenen kunnen onmogelijk getuige zijn van hun eigen verdwijning, en zolang ze in de gevangenis zitten, zijn ze ook voor hun beulen niet 'verdwenen'.

De zoektocht van de families kent dan ook verschillende fasen. Aanvankelijk hopen ze de gevangenen nog levend terug te vinden. Geleidelijk begint het echter te dagen dat de slachtoffers weleens dood kunnen zijn; later wordt duidelijk dat er enkel lijken gevonden zullen worden - als er al iets wordt gevonden. ${ }^{9}$ Het zwaartepunt van de acties verschuift in de loop van dit proces, maar ook het discours verandert en spitst zich toe op twee belangrijke eisen: waarheid en gerechtigheid. Omdat geen van beide wordt ingewilligd, zajente 作 en blijven verbeten het verhaal van hun verdwijning vertellen aan de samenleving.
De AFDD is werkzaam op twee fronten: ze concentreert zich op administratief werk in de coulissen en voert actie in de publieke ruimte. De eerste taak bestaat erin juridische stappen te ondernemen die kans bieden op een doorgedreven onderzoek naar de gebeurtenissen. Daarnaast, en dan vooral vanaf 1977, gaan de families ook de publieke ruimte innemen: ze voeren hongerstakingen, demonstreren, en maken objecten die de burgers aan hun strijd moeten herinneren. Tijdens een van hun meest spectaculaire campagnes lieten actievoerders zich vastketenen aan de hekken van het congres. De protesten waren verboden en werden meteen gepareerd, mo therd, maar de politie kon niet onmiddellijk tot arrestaties overgaan. In de chaos vonden de demonstranten tijd om voorbijgangers aan te spreken en de aandacht te vestigen op het gewelddadige verleden van het schijnbaar vredige Chili.

Het was de bedoeling van de AFDD om gebeurtenissen die officieel werden ontkend, zichtbaar te maken en onder de loep te nemen. Verder stelde de vereniging de vraag naar de plaats van het individu in het geheel - een vraag die ieder voor zichzelf, en samen met anderen, dagelijks moest zien te beantwoorden. De slogans die de AFDD gebruikte tijdens de demonstraties zeggen veel over hun houding in dat debat. De leden droegen grote plakkaten met foto's van de gezochte personen, en als enige opschrift: ‘Waar zijn zij?' We moeten de 'verdwenen personen' zoeken, zo luidde hun standpunt, omdat iedereen wel de geliefde is van iemand. Zelden speelden emoties zo'n doorslaggevende rol in een politiek verhaal. De liefde van de familieleden voor de verdwenen personen lag aan de basis van hun engagement en gaf hun acties in de

Wij houden van hen om wat ze waren: vrij in hun denken en rechtvaardig in hun volharding. Wij houden van hen omdat ze leiders waren van volkspartijen en vakbonden, mensen die in hun beroepsleven streden voor verandering en voor het leven. De redenen waarom wij van

hen houden, zijn ook de redenen waarom zij moesten verdwijnen. Zeventien jaar na deze misdaad tegen de menselijkheid doet hun afwezigheid nog evenveel pijn als de eerste dag. ${ }^{10}$

De missie van de AFDD - onderzoek voeren, misdaden aan het licht brengen, een maatschappelijk debat aanwakkeren - is in feite een politieke strijd. De moeders, vrouwen en zusters van de 'verdwenen' gevangenen profileren zich in de publieke ruimte als vertegenwoordigsters van politieke actoren, terwijl ze in de schaduw geheel volgens de regels van de stijl juridische aanklachten indienen.

GETUIGEN IN DE PLAATS VAN HET SLACHTOFFER

Samen met de juridische afdeling van het Vicariaat van de Solidariteit heeft de AFDD dossiers geopend met informatie over de gezochte personen - later zou men hen 'verdwenen gevangenen' A Aanvankelijk diendendedocing voor te bereiden, later werden ze gebruikt om verder onderzoek in te stellen. Bij de opening van de zaken, meestal na 1989, hebben ze ook effectief een belangrijke rol gespeeld.
(10) Toespraak uit 1991 van vereniging vanaf de oprichting to 
WHILI

Wat als de slach
spoorloos zijn?
(vervolg)

(11) www.vicariadelasolidaridad.cl

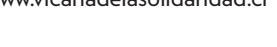

- No+ (Nooit meer) de leuze van het
Chileense verzet.
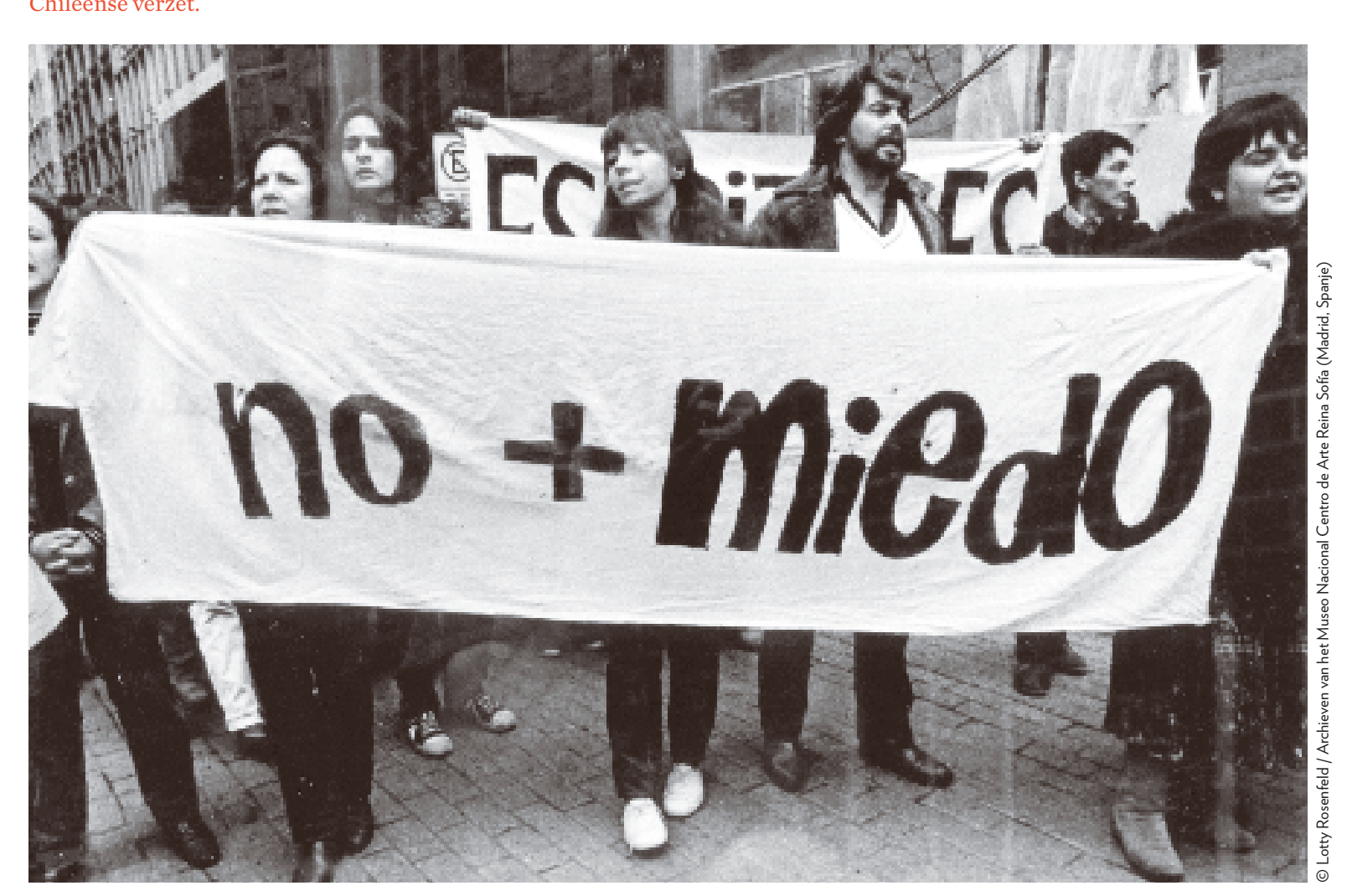

Tijdens de processen luidde de aanklacht echter niet 'ontvoering', want die misdaad stond niet in het wetboek. De punten van tenlastelegging waren 'andere': het waren willekeurige executies, of ontvoeringen onder verzwarende omstandigheden

De AFDD beschikte over twee soorten documenten. In de eerste plaats informatiedossiers (carpetas) met fiches over het slachtoffer, maar ook getuigenissen over de aanhouding en eventueel over de opsluiting. Wanneer het gerecht tussenkwam, en zolang het onderzoek lopende was, werden bovendien onderzoeksdossiers (expedientes) bijgehouden Dat archiefmateriaal is vandaag sedeltelijk beschikbear voor het tes) bijich wie de Fundación de Documentacióny Archivo Ex Vicaría de la Solidaridad. Wie de dossiers erop naslaat, begrijpt meteen hoe moeilijk het indertijd was is het slachtoffer, nu zoeken we de schuldige': die vertrouwde manier van werken was geen optie. Het feit dat de lichamen nooit werden teruggevonden, wat op zich erg uitzonderlijk is, wekte argwaan. De militaire junta speelde daar handig op in en heeft het bestaan van de verdwenen gevangenen altijd systematisch ontkend. Een sleutelmoment in deze geschiedenis was de grootschalige perscampagne van ig75, in zekere zin een eerste officiele reactie op de vele vragen over het lot van de niet-erkende gevangenen. Het regime nam hierin een uitgesproken negationistische houding aan: het wilde de bevolking doen geloven dat de gezochte personen naar de buurlanden waren gevlucht en elkaar daar hadden uitgemoord. Deze campagne staat bekend als 'Operatie Colombo' of de zaak van de 'lijst van de 119', en vormde een keerpunt voor de AFDD. Vanaf dat ogenblik beseften de families dat de overheid de misdaden opzettelijk toedekte en dat ze hun geliefden waarschijnlijk niet levend zouden terugvinden.

Over de benoeming van de slachtoffers bestond grote onenigheid. De overheid, die de misdadige praktijken bleef ontkennen, had het over 'zogezegd verdwenen personen'. Erger nog, in 1977 trok de Chileense ambassadeur bij de Verenigde Naties het wettelijk bestaan van de slachtoffers in twijfel. Hij beweerde dat ze niet bestonden - dat ze nooit geboren waren. Als dan ook hun lijken niet worden teruggevonden, begrijpt men het ongeloof bij de bevolking. De belangrijkste taak van de AFDD bestond er dus niet zozeer in de misdaad aan te tonen, maar bewijs te leveren van het bestaan van de slachtoffers.

De eerste verhalen die werden opgetekend door het Vicariaat waren beëdigde verklaringen. Zo'n verklaring bevatte een aantal vaste elementen. Men deed eerst een korte mededeling, bijvoorbeeld: 'Tk verklaar onder ede dat mijn zoon tegen zijn wil is verdwenen (j) vraag ikeen schuldigen." Meteendaar van de gezochte persoon inclusief foto, naam, geboortedatum en -plaats, en burgerlijke staat. Daarna kwam het verhaal van diens aanhouding, en aan het eind een samenvatting van de acties die al waren ondernomen om de persoon terug te vinden. Het behoeft geen betoog, maar toch willen we dit nog even onderstrepen: wie een aanklacht durfde te formuleren tijdens de dictatuur, zelfs officieus binnen het Vicariaat, had een buitengewoon doorzettingsvermogen nodig en een uitstekende kennis van de gezochte persoon. Er moest immers een gedetailleerde fiche worden opgesteld van het slachtoffer. Parallel met de zwarte lijsten van de inlichtingendiensten creëerde de AFDD een 'witte' lijst om de personen die waren ontvoerd door
het militaire regime weer zichtbaar te maken.

In de dossiers lezen we verhalen van mensen wiens leven op een bepaald moment volledig is omgegooid, zonder te weten wat hen precies is overkomen. Maar er zijn niet alleen de verhalen. De dossiers bevatten ook foto's, geboorte- en huwelijkscertificaten, schooldiploma's - diverse officiële documenten die samen een bewijs vormen van het bestaan van iemand vóór diens verdwijning. Na verloop van tijd ging men ook persoonsbeschrijvingen toevoegen waarin bijzondere uiterlijke kenmerken werden vermeld. Vandaag is dat essentiële informatie om de stoffelijke overschotten te identificeren. Herinneringen van familieleden gaan zo een fundamentele rol spelen in de samenstelling van de dossiers en de juridische procedure De herinnering is namelijk niet alleen praktisc praktisch gezien kan enkel iemand die hen heel goed kende, voldoende details geven
over de slachtoffers om een aanklacht in te dienen. (12) Stichting Documentatie en
Archieven Ex Vicariaat van de 
WHILI

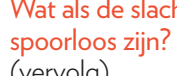

Het verhaal van de verdwijning wordt altijd door een ander verteld. Geen enkele 'verdwenen persoon' in Chili is ooit teruggekomen. Geen enkele kan spreken in eigen naam, zijn of haar verhaal doen, de slachtofferrol opnemen, eisen stellen. Moesten deze personen in de gevangenis de tijd hebben gehad om hun situatie in te zien en te beseffen dat ze waren 'verdwenen' voor de buitenwereld, dan zouden ze waarschijnlijk nooit die term hebben gebruikt. Zo spraken zij niet over zichzelf. Net daarom zijn de families zo terughoudend: ze willen in geen geval de plaats innemen van het echte slachtoffer door zichzelf als slachtoffer te profileren...

\section{DE MOEIZAME ERKENNING VAN DE SLACHTOFFERS}

tenzij ze zich persoonlijk en rechtstreeks gekwetst voelen. Dat soort gevoelens wordt zelden tentoongespreid tijdens openbare manifestaties, maar steekt af en toe de kop op in gesprekken tussen familieleden en psychologen - met andere woorden, gesprekken waarin de families niet het 'officiële' standpunt van de vereniging vertolken. Het is niet zo dat zij hun gevoelens ontkennen of weigeren de slachtofferrol in te vullen, maar ze beschouwen het gewoon niet als een prioriteit. ${ }^{13}$

Later zouden de families met nieuwe moeilijkheden geconfronteerd worden. Bij de democratische overgang in 1989 ging de regering de term 'slachtoffer' de dencticiciee gerechtigheid werd niet ingewilligd. Dat lijkt misschien tegenstrijdig, maar dat is het niet. In feite weigerde de regering de politieke dimensie van het verhaal te erkennen - niet zozeer van de misdaad op zich, maar van diens onthulling. De kwestie stelde uiteindelijk alle regeringen na 1989 voor een groot probleem: de democratische leiders zagen zich verplicht mensen naar de beklaagdenbank te brengen waarmee ze de terugkeer naar de democratie hadden onderhandeld. Ondertussen, na jaren van spanningen en conflicten, zijn uiteindelijk toch processen opgestart en straffen uitgesproken. Het huidige systeem van strafvermindering veroorzaakt echter veel wrevel, omdat de schuldigen soms erg snel weer vrijkomen.

De erkenning van de slachtoffers hebben we te danken aan de publicatie van Ret Rapport van de Nationte conmisse van wathe de (het betogen, ma bij rapro In 1991 w In 1991 wordt het laatste beetje argwaan weggenomen: men spreekt niet meer ove 'zogezegde gevangenen' maar over 'verdwenen gevangen'. Nu het lot van de vermoorde mensen (volgens het rapport slachtoffers van politieke terechtstellingen) bekend is, worden maatregelen uitgewerkt om de families een schadevergoeding toe te kennen.

Het dictatoriale regime is echter niet het enige dat zwaar in de fout ging. Ook de democratische leiders hebben beslissingen genomen die de families veel kwaed hebben berchend Ophetalgemeen kerkh op fouten in het onderzoek. De regering besloot de zaak in de doofpot te stoppen. Onder het presidentschap van Michelle Bachelet kwa alles aan het licht: de lichamen waren onder een valse identiteit begraven. Bachelet verzocht om een tegenexpertise, maar het kwaad was al geschied. Deze nieuwe tragedie heeft het rouwproces van de families danig in de war war gesturd. In 2011 wen zij door de staat dan ook vergoed voor de fouten in het identificatieproces. De voorzitster van de AFDD, Lorena Pizarro, toonde zich tevrede met deze belangrijke beslissing 'voor al wi slachtoffer werd van gedwongen verdwijningen en politieke terechtstellingen, en eronder heeft geleden - het is een belangrijke beslissing voor ons. ${ }^{14}$

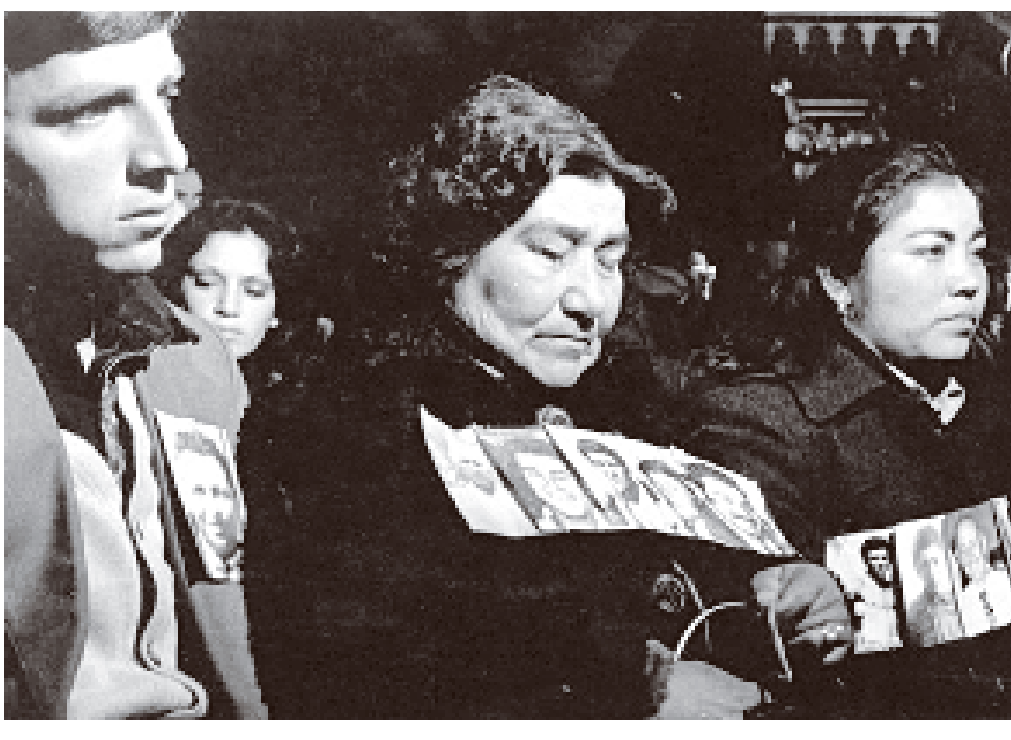

\section{DAAR ZIJN GEEN WOORDEN VOOR}

De beulen hebben zo hun eigen manier om over de gebeurtenissen te spreken. De uitdrukking 'verdwenen gevangenen' komt niet van hen, zoveel is duidelijk. In
Chili zijn het in de eerste plaats de AFDD en het Vicariaat van de Solidariteit die Chili zijn het in de eerste plaats de AFDD en het Vicariaat van de Solidariteit die
de misdaden hebben benoemd. De dossiers die zij opstelden, zijn later gebruikt de misdaden hebben benoemd. De dossiers die zij opstelden, zijn later gebruikt om via een officiële procedure het statuut van de slachtoffers vast te leggen. Dat proces werd opgestart onder de eerste democratische regering en afgerond onder landen hun internationale acties op. Sinds 23 december 2010 is zo de 'Internationale conventie terbeschermingvan personen tegen redwongen verdwijning' van kracht, een verdrag dat ook de Chileense staat ondertekende.

In een tijd van dictatuur waarin de leugen regeert, is het van cruciaal belang om de slachtoffers te erkennen en correct te benoemen. De familieleden van de verdwenen gevangenen hebben natuurlijk geen exclusief recht op de term 'slachtoffer', die steeds op een andere manier wordt ingevuld. In de Chileense context zijn de burgers echter gaan reflecteren over dat wat hen verbindt met de ander. De valorisatie van de familieband tijdens manifestaties heeft hen aan het denken gezet. De Chilenen zien nu in dat de protesterende moeders, echtgenotes en dochters zich nooit hebben laten afschrikken door het militaire bewind. Door de jaren heen zijn deze vrouwen blijven vertellen over hun geliefden en hebben ze belangrijke vragen gesteld aan de samenleving. De vraag naar het lijden werd bijvoorbeeld herhaaldelijk gesteld - en bleefonbeantwoord Mar de meest prangende politieke vrag is wel deze: waarom bleft dij warom en vrouwen die 'vrij waren in hun denken en rechtvaardig in hun volharding'.
- Mis opgedragen aan de gevangen en Santiago: naasten van de
slachtoffers in de Recolet Franciscanakerk, september 1979.

(14) Lorena Pizarro op Radio 2011. (15) In 1996 publiceerde de waarheid en gerecchtigheid een tweede rapport over de
slachtoffers van schendingen van mens.
geweld. Nationale commissie van 